\title{
Economic Theory and Self-Reported Measures of Presenteeism in Musculoskeletal Disease
}

\author{
Cheryl Jones $^{1,2}$ - Katherine Payne ${ }^{1} \cdot$ Brenda Gannon $^{1}$ - Suzanne Verstappen ${ }^{3,4}$
}

Published online: 11 July 2016

(C) The Author(s) 2016. This article is published with open access at Springerlink.com

\begin{abstract}
This study had two objectives: to describe the historical development of self-reported presenteeism instruments that can be used to identify and measure presenteeism as a result of musculoskeletal disease (MSD) and to identify if, and how many of these, presenteeism instruments are underpinned by economic theory. Systematic search methods were applied to identify self-report instruments used to quantify presenteeism caused by MSD. A total of 24 self-reported presenteeism instruments were identified; 24 were designed for use in general health, and 1 was specifically designed for use in rheumatoid arthritis. One generic self-reported presenteeism instrument was explicitly reported to be underpinned by economic theory. Overtime, self-reported presenteeism instruments have become more differentiated and complex by incorporating many different contextual factors that may impact levels of presenteeism. Researchers are encouraged to further develop presenteeism instruments that
\end{abstract}

This article is a part of Topical Collection on Health Economics and Quality of Life

Suzanne Verstappen

suzanne.verstappen@manchester.ac.uk

1 Manchester Centre for Health Economics, The University of Manchester, 4th Floor, Jean McFarlane Building, Oxford Road, M13 9PL Manchester, UK

2 Arthritis Research UK/MRC Centre for Musculoskeletal Health and Work, University of Southampton, Southampton, UK

3 Arthritis Research UK Centre for Epidemiology, Centre for Musculoskeletal Research, Institute of Inflammation and Repair, The University of Manchester, Manchester Academic Health Science Centre, Stopford Building, Oxford Road, M13 9PT Manchester, UK

4 NIHR Manchester Musculoskeletal Biomedical Research Unit, Central Manchester NHS Foundation Trust, Manchester Academic Health Sciences Centre, Manchester, UK are underpinned by relevant economic theory and informed by robust empirical research.

Keywords Systematic review · Self-report presenteeism instruments $\cdot$ Musculoskeletal diseases $\cdot$ Economic theory

\section{Introduction}

Since 1990, the global burden of musculoskeletal diseases (MSDs), including chronic rheumatological conditions, as measured by disability-adjusted life years (DALYs), has been shown to increase dramatically [1]. For many chronic rheumatological conditions, such as rheumatoid arthritis (RA), psoriatic arthritis (PsA) and ankylosing spondylitis (AS), disease onset can occur at any age; however, peak incidence rates have been found to occur between the ages of 40 and 65 years [2]. Previous reviews have estimated that within 13 years after onset RA, the probability of becoming work-disabled is $50 \%$ $[3,4]$. Similarly, after 5 years of the onset of AS, up to $13 \%$ of adults are likely to lose their jobs [5]. The reduction in health status in people with these diseases will not only affect their daily functioning, and cause early mortality, but may also have a major impact on their productivity at work (productivity loss). In the last two decades, there have been some advances in the treatment of MSD, but these strategies are not curative and many people still experience productivity loss [6-8].

Productivity can be viewed, within the context of the employment environment, as a measure of technical efficiency that examines how inputs, such as labour and capital (technology), are used to produce outputs of sufficient volume and quality [9]. The productive rate of any individual may be affected by a variety of factors such as job demands, levels of support, working hours, job satisfaction and, perhaps most importantly, poor health. The impact of a reduction in health 
status has been directly linked to productivity loss through absenteeism and presenteeism. Absenteeism refers to the time (hours, days, weeks) spent away from work because of illness [10-13], and presenteeism refers to the reduction in 'working performance whilst at work due to ill health' [14].

It is relatively easy to objectively quantify absenteeism using simple counts of days away from work. Quantifying the impact of presenteeism is much more challenging, involving two stages: (1) identifying and measuring the volume of unproductive time and (2) valuing the impact of that unproductive time. The lack of available objective measures that can be used to identify and measure presenteeism has led to the development of instruments that rely on self-reports from the individual affected by an adverse health condition, such as a MSD.

A number of reviews have systematically identified a number of instruments, both general health and disease-specific, that are available to self-report presenteeism. Some of these systematic reviews have focused on how to identify and measure presenteeism and found that the available instruments differed extensively and lead to vastly different estimations of the volume of presenteeism $[11,15,16]$. In contrast, the methods used to value the impact of presenteeism has largely focused on using two, similar, methods that centre on using cost as the unit of measurement: the human capital approach (HCA) and the friction cost approach (FCA) [17]. The HCA and FCA value the amount of productivity loss by multiplying the amount of time an individual is unproductive during a working week by the wage rate. The two methods differ in terms of the perspective they take. The HCA calculates the cost of lost productivity from the perspective of the patient/ employee. Therefore, the cost of lost productivity continues until that individual employee/patient has found another job. The FCA takes an employer perspective and calculates the cost of lost productivity based on the amount of time it takes to replace the sick employee; this period of time is known as the 'friction' period. Once the sick employee has been replaced, the FCA assumes that initial production levels are restored [17]. The HCA and the FCA are grounded in economic theory that assumes that productivity is equal to the market wage which represents the marginal revenue product of labour of an employee working for an employer in the context of a perfectly competitive market [18]. Two studies by Pauly et al. [19] and Zhang et al. [12] criticise the economic theories that are used to underpin methods that value the cost of lost productivity. Pauly et al. suggested that the allowances for sick days and protection against fluctuating wages will mean that employees will accept a wage rate that is lower than the value of the marginal productivity of the worker. Therefore, the value of productivity loss will exceed the value of the wage because the wage is lower than marginal productivity. Similarly, Zhang et al. argued that the cost of productivity loss will exceed the value of the wage rate if a job involved team-based work, unavailability of substitutes, and produces highly time-sensitive output.

It is important to understand the theoretical underpinning of an approach to quantify the impact of a subjective construct, such as presenteeism, to enable the development of a robust approach to its identification, measurement and valuation. Economic theories provide a common framework from which to develop methods that can be used to identify and measure the impact of presenteeism. To our knowledge, it is currently unknown which, if any, self-reported presenteeism instrument used to identify and measure presenteeism is underpinned by economic theory. This study had two objectives: (1) to describe the historical development of self-reported instruments that can be used to identify and measure presenteeism as a result of a MSD and (2) to identify if, and how many of these, self-reported presenteeism instruments are underpinned by economic theory.

\section{Methods}

A systematic review was carried out to identify all published studies that describe the development of self-reported presenteeism instruments that can be used in MSD. The search was run up until November 2015. The systematic review was conducted, in line with advice and guidelines published by the Centre for Reviews and Dissemination (CRD) [20] and followed the Preferred Reporting Items for Systematic Reviews and Meta-Analyses (PRISMA) checklist.

\section{Search Strategy}

The search for relevant studies involved updating a recent systematic search conducted by Ospina et al. in 2012 [21•]. Ospina et al. conducted a systematic search that identified all general health and disease-specific presenteeism instruments. The electronic search strategies used by Ospina et al. (see Appendix) were retrieved and re-ran in eight electronic databases including Medline (1946 to September week 3 2015), Embase (1980 to week 40 2015), Cochrane Central Register of Controlled Trials (CENTRAL) (August 2015), PsychINFO (1806 to September week 4 2015), Web of Science (1900 to November 6, 2015), CINAHL (1937 to November 6, 2015), Business Source Complete (1886 to November 6, 2015) and ABI inform (1970 to November 6, 2015). The electronic search strategies comprised of the specific names of presenteeism instruments, such as the 'Endicott work productivity scale' and more generic terms such as 'productivity' and 'presenteeism'. The new search was constrained to run between 1st January, 2012 to 6th November, 2015. 


\section{Study Selection Process}

All titles and abstracts identified were double screened for inclusion by two independent reviewers (CJ and either KP, $\mathrm{BG}$ or $\mathrm{SV}$ ) and accepted if the study met the inclusion criteria specified in Table 1.

\section{Data Extraction and Synthesis}

One reviewer (CJ) extracted the data from each study using a bespoke data collection form to extract author, year and country that the study was completed; name of the presenteeism instrument; aims of the instrument; whether the instrument also measured absenteeism; the structure of the instrument; recall period used; whether estimations of presenteeism using that specific instrument could be converted into monetary values using the HCA or FCA; and clear reporting of the economic theories used to underpin the presenteeism instrument developed. The results were tabulated and summarised as part of a narrative synthesis.

\section{Results}

In total, 24 studies that described the development of presenteeism instruments for use in MSD were identified. Of these, the Work Productivity Survey for Rheumatoid Arthritis (WPS-RA) [22] was the only one designed to specifically measure presenteeism associated with a MSD (RA). The remaining 24 presenteeism instruments were developed for use across a wide range of health conditions, including MSD. Figure 1 illustrates the identification and inclusion of relevant studies. A summary of the identified presenteeism instruments are presented in Table 2 .

\section{Self-Reported Presenteeism Instruments: a History}

The earliest identified measure of presenteeism, the Work Performance Scale (WPS), was designed by Jette et al. in 1986 [23]. The WPS asks the respondent to rate their ability to function physically, mentally and socially. The measure is simple and originally designed for clinical use. In 1993, Reilly et al. (1993) developed the Work Productivity Activity Index (WPAI) which differs substantially to the WPS. The WPAI asks the respondent to state the number of days missed from work and the number of days they found work difficult. The instrument also asks about productivity loss when doing unpaid work.

By the late 90's and early 2000's, presenteeism instruments were being designed to collect additional information regarding the contextual factors of an individual's occupation. For example, the Occupational Role Performance Questionnaire (ORQ) developed by Kopec and Esdaile in 1998 [27] collects information about the individual's job satisfaction, job security and the quality of the relationships they have with their colleagues. The Work Instability Scale (WIS) developed by Gilworth et al. in 2003 [34] asks questions about the respondent's work situation and physical work factors.

In 2004, Stewart et al. [39] developed the Work Health Interview (WHI). The WHI is a telephone interview designed to collect information that can be used to estimate the cost of productivity loss. The interview introduces questions about the type of work tasks individuals are expected to complete as part of their job. The WHI is one of the first instruments that explicitly take into account how job characteristics may affect levels of presenteeism. In 2012, Zhang and colleagues developed the Valuation of Lost Productivity (VOLP) questionnaire [43•], a presenteeism instrument that explicitly takes into account how factors such as team dynamics, availability of perfect substitutes and time sensitivity of outputs either compensate or multiply levels of productivity loss caused by health conditions. Since 2015, presenteeism instruments, including the Composite Work Functioning Approach [44] and the

Table 1 Inclusion criteria

\begin{tabular}{|c|c|c|}
\hline & Inclusion criteria & Exclusion criteria \\
\hline \multirow[t]{2}{*}{ Study type } & Development of method that quantifies presenteeism & Studies that apply the developed method, for example, in economic evaluations \\
\hline & & $\begin{array}{l}\text { Studies that test methods of presenteeism in terms of their psychometric } \\
\text { properties and do not discuss the development of the instrument }\end{array}$ \\
\hline \multirow[t]{4}{*}{ Focus } & $\begin{array}{l}\text { Methods developed for assessing health-related } \\
\text { presenteeism }\end{array}$ & Methods developed for assessing other forms of productivity loss, e.g. shirking \\
\hline & $\begin{array}{l}\text { Methods developed for assessing generic health or } \\
\text { musculoskeletal conditions }\end{array}$ & $\begin{array}{l}\text { Methods developed that focus on disease-specific areas except musculoskeletal } \\
\text { conditions, e.g. mental health }\end{array}$ \\
\hline & Original development of presenteeism methods & Adaptations of methods for use in other countries, e.g. WLQ-J \\
\hline & & $\begin{array}{l}\text { Adaptations of methods for use in specific disease areas if the original was } \\
\text { developed for general health }\end{array}$ \\
\hline $\begin{array}{l}\text { Publication } \\
\text { type }\end{array}$ & English language & Foreign languages \\
\hline
\end{tabular}


Fig. 1 Flow diagram of study selection process

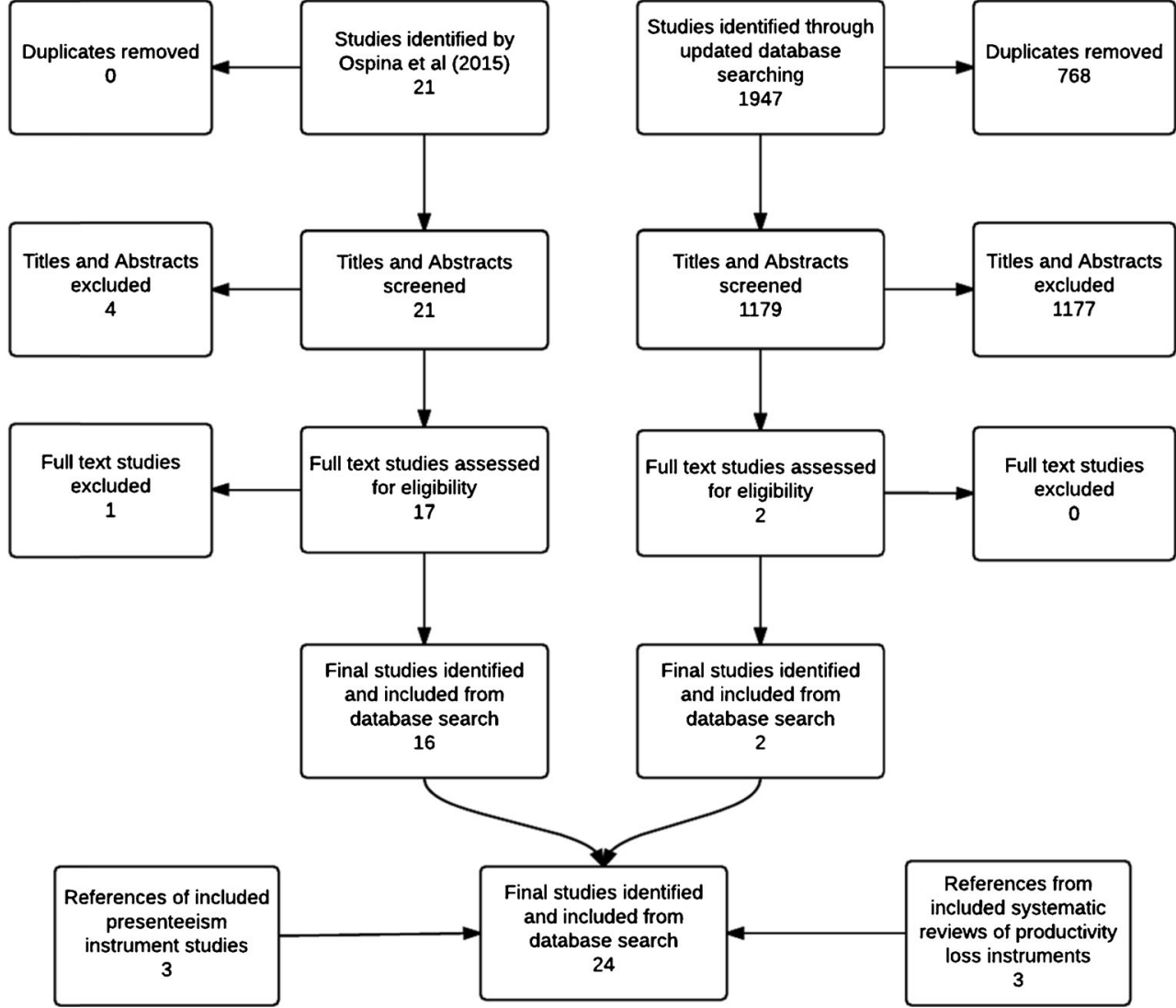

iMTA Productivity Cost Questionnaire (iPCQ) [45], have been developed using questions from pre-existing measures including the Work Limitations Questionnaire (WLQ) [31], the Health Limitations Questionnaire (HLQ) [25] and the Productivity and Disease Questionnaire (PRODISQ) [46] rather than developing another completely new presenteeism instrument.

\section{Economic Theory Underpinning Presenteeism Instruments}

Of the 24 studies that report the development of presenteeism instruments, only one study by Zhang et al. (2012) [43•] discussed how economic theory was used to underpin the design of their presenteeism instrument. They explain the economic rationale behind the development of their presenteeism instrument, the VOLP. The VOLP was designed to identify and measure productivity loss associated with various chronic health conditions and was validated using a sample of employees working with rheumatoid arthritis. Zhang et al. state that the concept of productivity is based on the theory of the production function, where output is a function of inputs including labour, capital and technology. Based on the economic theory of the production function, the authors define productivity loss due to ill health as the output loss associated with reduced labour input. Zhang et al. highlighted that no other existing presenteeism instrument captures both time input loss and information about workplace/job characteristics. The aim of the VOLP is to capture this information so that it can be used to measure productivity loss in terms of output loss associated with reduced labour input caused by ill health. Zhang et al. also critiqued the economics of valuing presenteeism using wage rates. Economic theory states that wages are assumed to be equal to the marginal productivity of workers. However, Zhang et al. argued that wages are often not an accurate reflection of the true value of productivity at the margin because of various other factors such as team production, availability of perfect substitutes and time sensitivity of outputs. Zhang et al. argue that these workplace and job characteristics need to be taken into account explicitly when attempting to measure productivity loss caused by ill health.

The remaining 23 studies stated that the motivation for the development of their presenteeism instruments was based on (1) the need to estimate the impact of presenteeism suitable for economic evaluations of healthcare and workplace interventions (18 studies: [22, 24, 25, 28-33, 35-42, 43•, 45]) and (2) the need to estimate individuals' ability to function at work (5 studies: $[23,26,27,34,44])$. No formal theoretical framework of presenteeism from an economic or other relevant discipline, for example psychology, was used to underpin the methods used by the remaining 24 presenteeism instruments. 


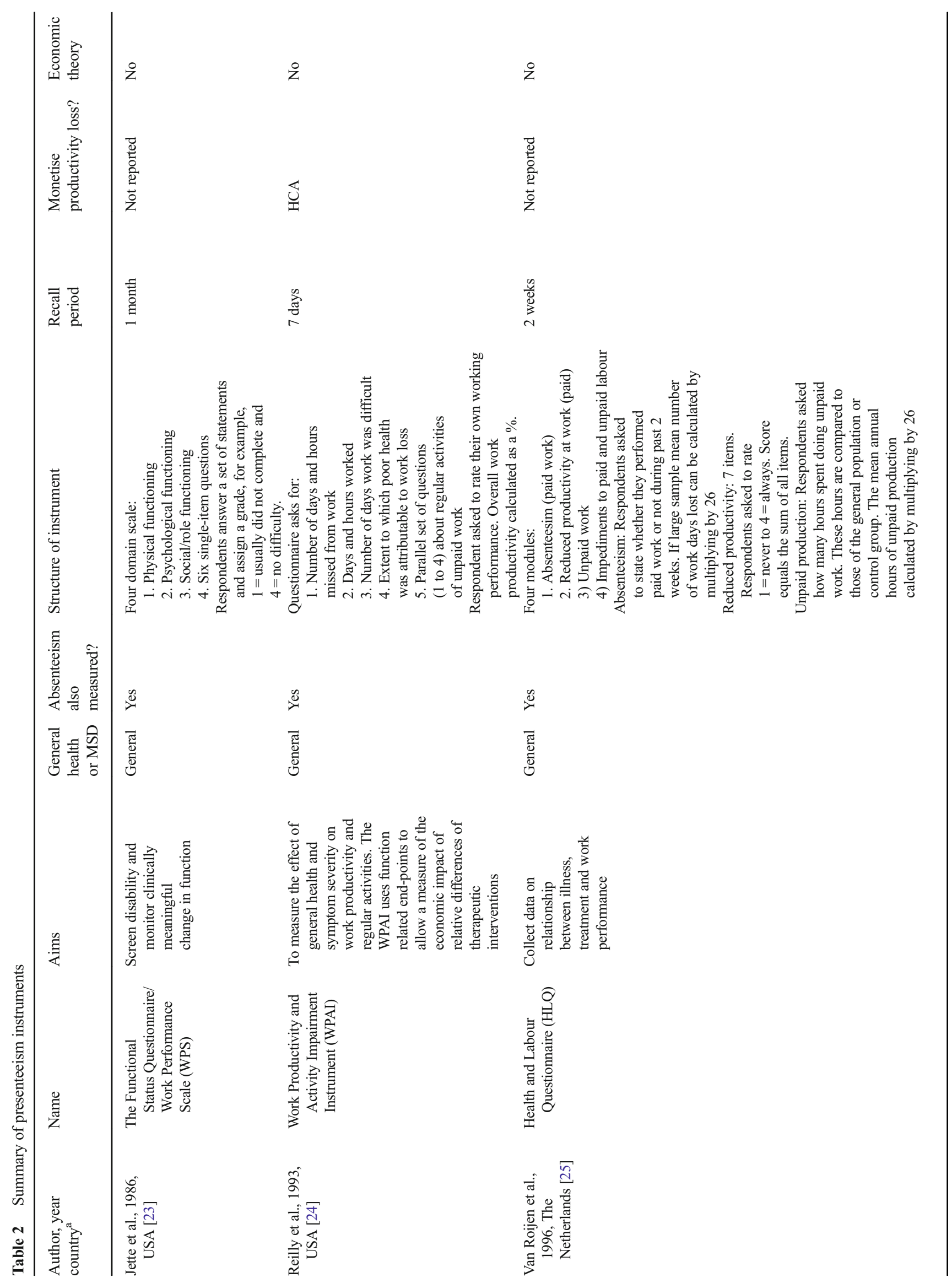




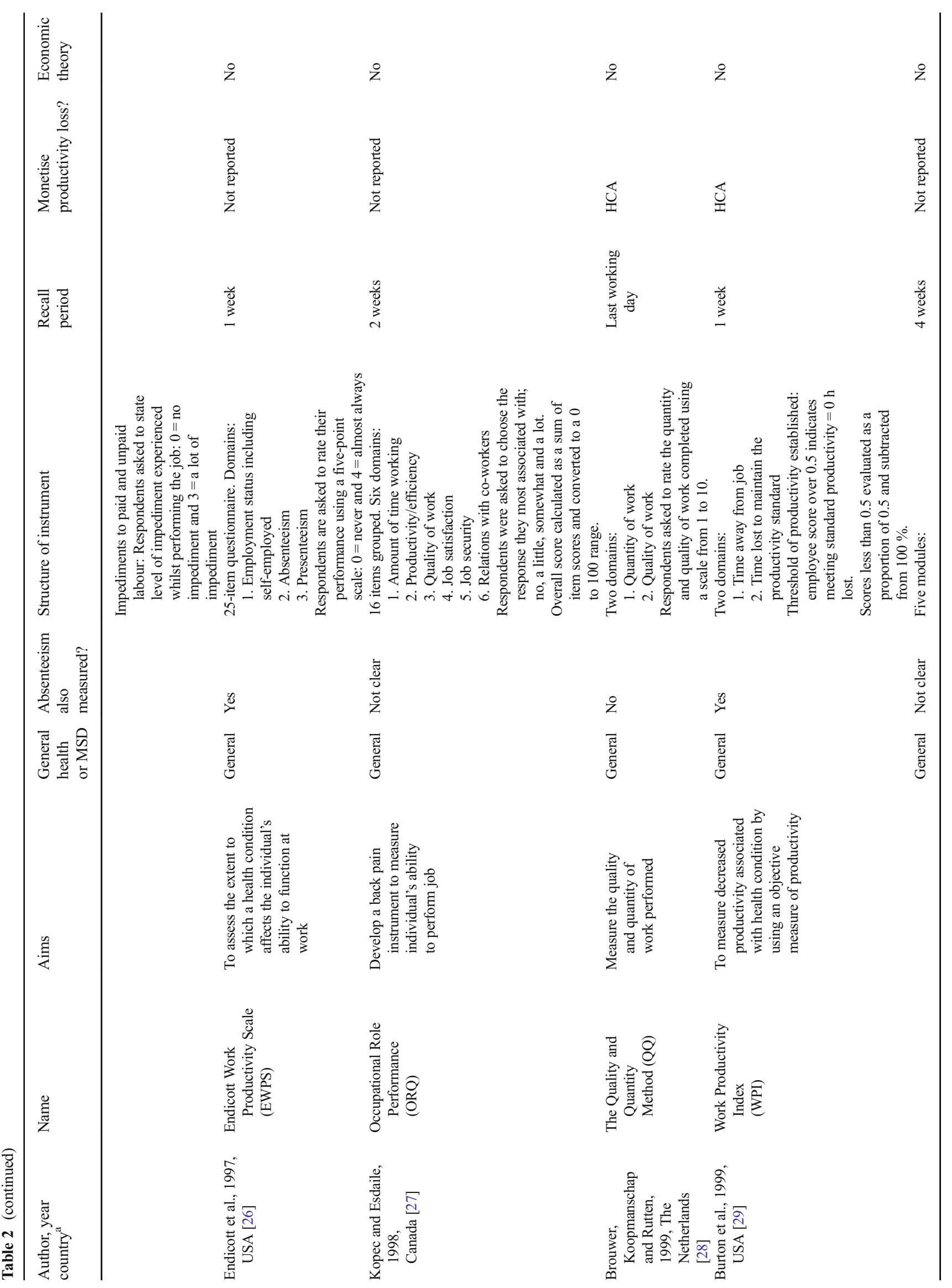




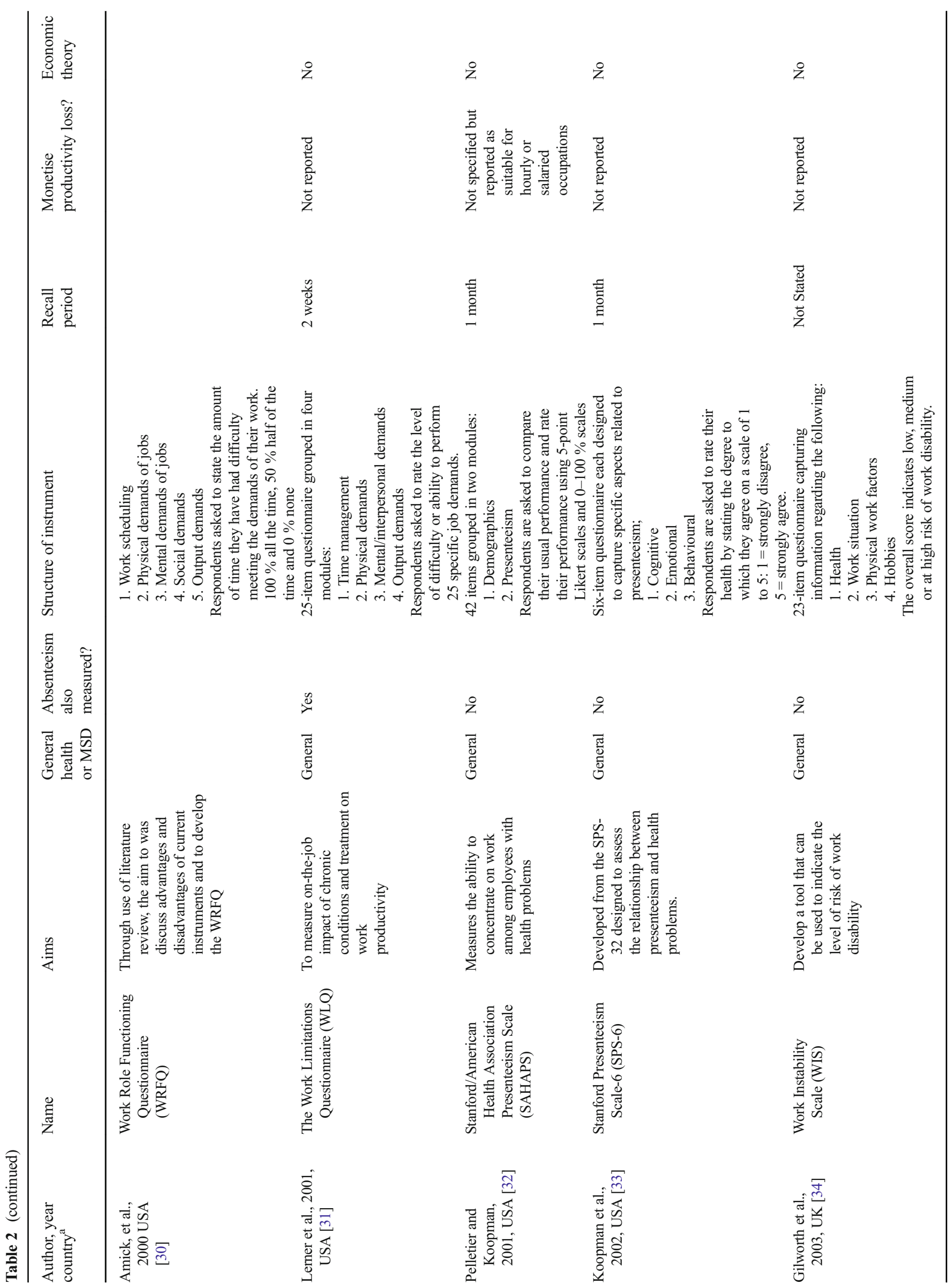




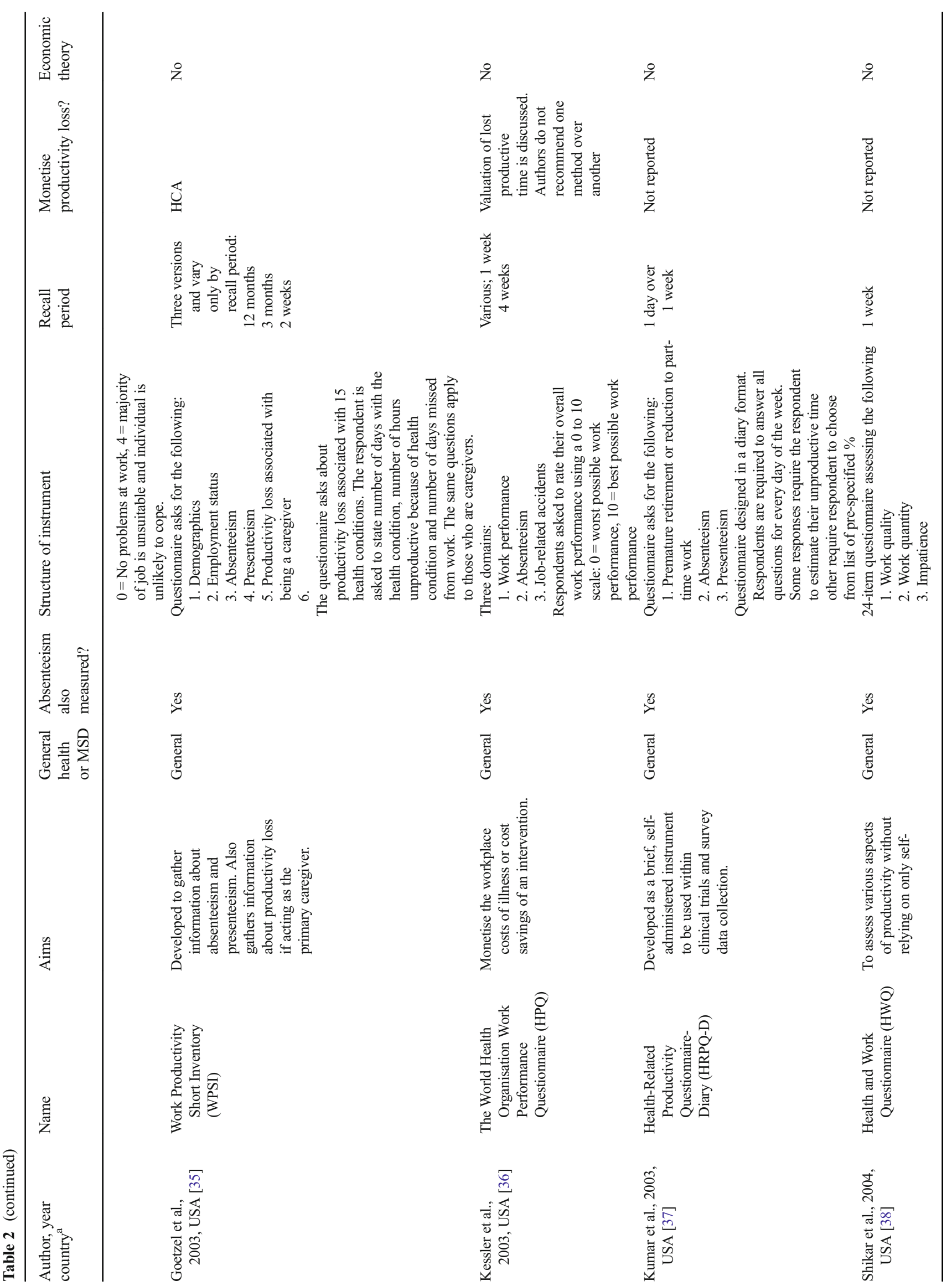




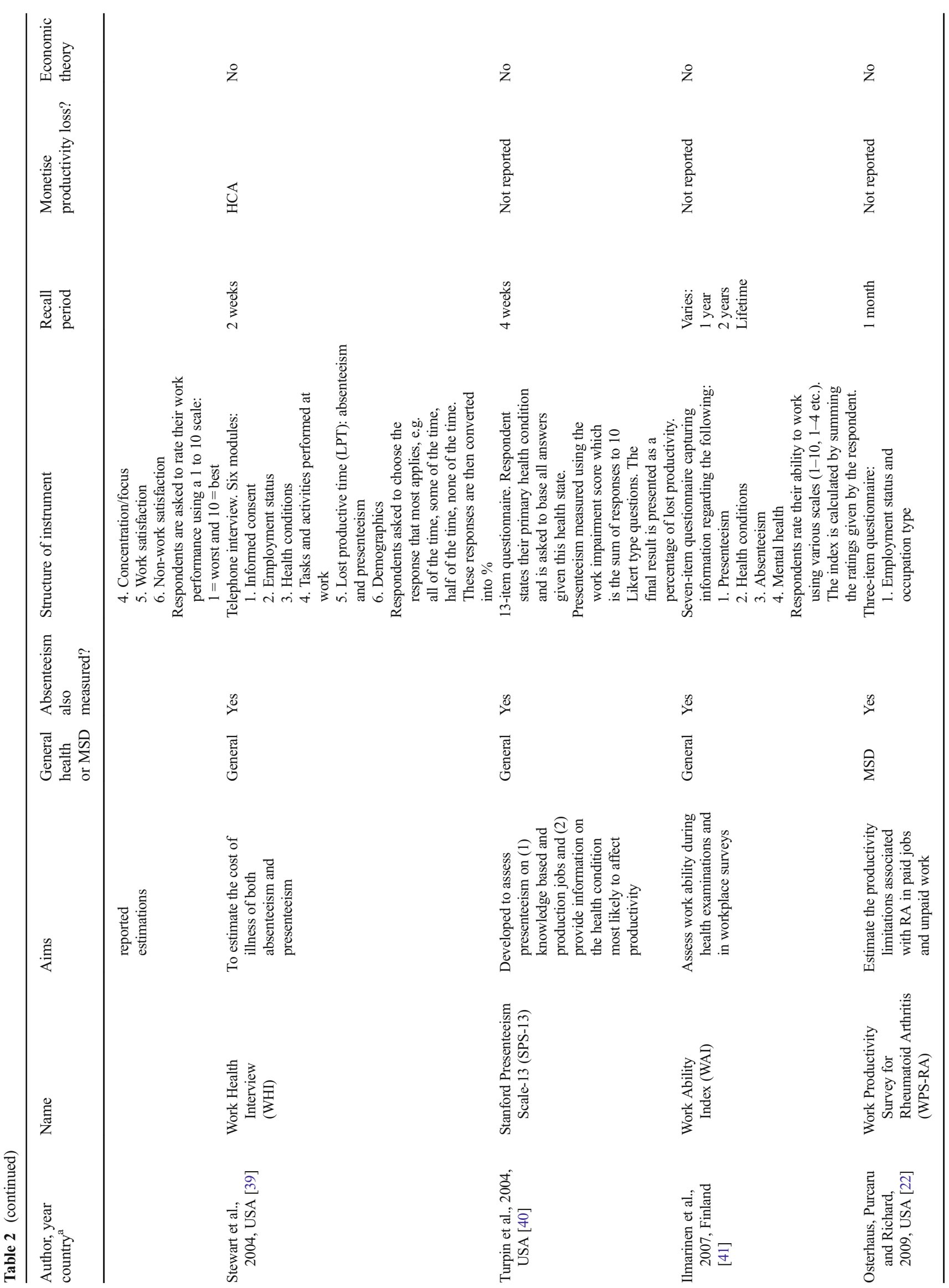




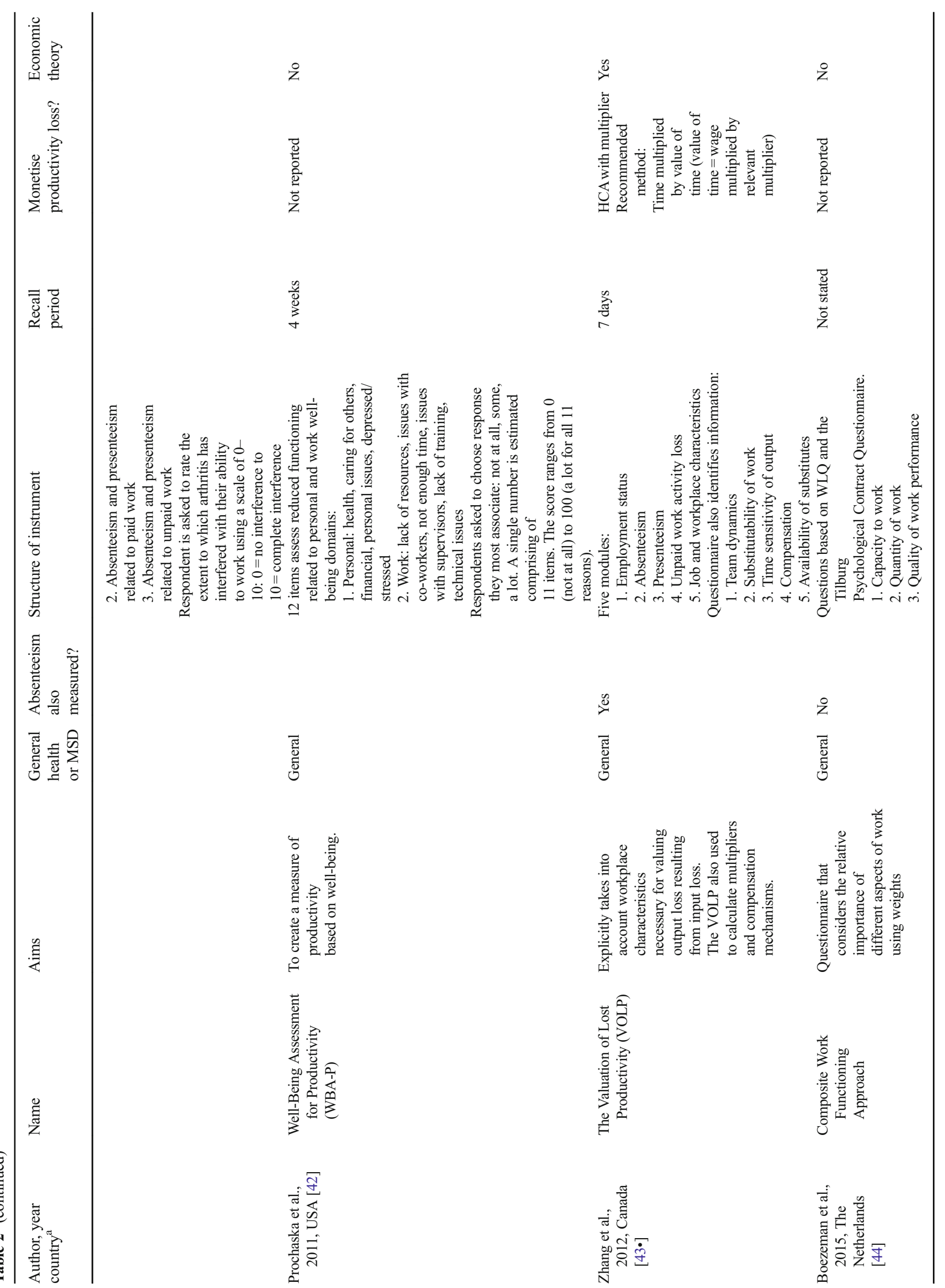




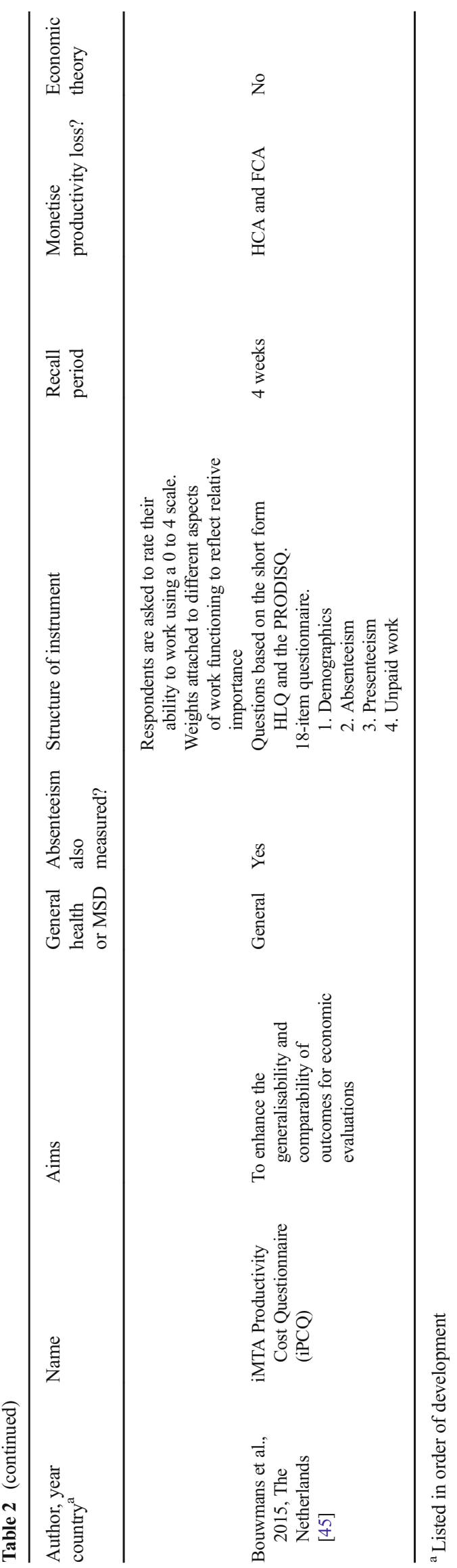

\section{Discussion}

This systematic review has identified a substantial number of self-report presenteeism instruments, and one of these was specifically designed for use in an MSD-related condition (RA). With one exception, the development of the existing instruments was not underpinned by economic theory. Currently, the majority of self-reported instruments are atheoretical, which is problematic because the rationale, construct and development of the instruments cannot be linked. Zhang et al. [43•] was the only study that described how the economic theory of productivity was used to inform the design of the VOLP. The advantage of underpinning the design of the VOLP with economic theory of productivity is that it is clear what the rationale of the VOLP was, how it was designed and how it should be interpreted and used. Zhang et al. [43•] argue that most presenteeism instruments in the literature focus on measuring an individual's labour input by measuring the time spent not working rather than the output lost from reduced labour. It is clear that in the absence of an economic theory of presenteeism, the interpretation of presenteeism from an economic viewpoint is contentious.

The absence of economic theory used to support the instrument to identify and measure presenteeism may have also contributed to the way in which researchers have approached the development of presenteeism instruments. The lack of a theoretical model for presenteeism means that researchers do not have a common framework from which to begin their research and develop their ideas. Therefore, as research into the measurement of presenteeism has grown, the instruments developed to quantify presenteeism have become more differentiated and more complex. The presenteeism instruments developed in the 1980s and 1990s are relatively simple where the respondent is asked to give information about their perceived level of absenteeism and presenteeism based on their health condition. In comparison, those presenteeism instruments developed in the late 2000s ask the respondent to consider a wide range of factors including job characteristics, team dynamics, timesensitive output, job satisfaction, job security and relationships with colleagues, as well as the direct impact on presenteeism caused by their health condition. Ospina et al. [21•] and Noben et al. [47] recommended that the development of more self-reported presenteeism instruments is not needed and instead the literature should focus their effort on improving the ones that already exist. To some extent, this is happening where the two latest presenteeism instruments, the composite work functioning approach and the $\mathrm{PCQ}$, use questions from pre-existing presenteeism instruments. However, it is not yet clear which instruments are the most appropriate for measuring presenteeism in the context of health conditions in 
general, and MSD, specifically. The OMERACT group are currently working towards recommending which of the available measures is best used in the context of rheumatoid arthritis [48]. However, taking into account economic theory suggests the need to define the best measure in terms of clearly specifying the three constituent parts (identification, measurement, valuation) to quantify the impact of presenteeism.

\section{Limitations}

The studies that were used to identify whether or not presenteeism instruments were developed using economic theory did not provide extensive detail. Many studies provided limited information that described how the presenteeism instrument was created. In an area where the quantification of a concept is subjective, such as presenteeism, it should be encouraged that researchers publish information about the conceptualisation and development of their presenteeism instrument. Such information would help inform the correct application and interpretation of their instrument, especially in the absence of applying an economic framework from which to underpin the instrument.

\section{Conclusions}

This review has systematically identified all self-reported presenteeism instruments, providing a historical context and whether presenteeism instruments are underpinned by economic theory. With the exception of the VOLP, none of the instruments are explicitly underpinned by economic theory. One key area for further research is to take account of the need to understand how to identify, quantify and value the impact of presenteeism, while underpinning these stages with relevant economic theory for each constituent part of this process. Economic theory would aid the correct interpretation and application of the selfreport presenteeism instrument and valuation approach. It is also vital that further development of presenteeism instruments are informed by robust empirical studies that take account of the context in which the final instrument will be used.

Acknowledgments This work was supported by Arthritis Research UK and the Medical Research Council [20665].

\section{Compliance with Ethical Standards}

Conflicts of Interest CJ, KP, BG and SV declare that they have no conflicts of interest.
Human and Animal Rights and Informed Consent This article does not contain any studies with human or animal subjects performed by any of the authors.

\section{Appendix. Electronic search strategies}

OVID databases:

Medline (1946 to September week 3 2015),

Embase (1980 to week 40 2015),

CENTRAL (August 2015)

PsycINFO (1806 to September week 4 2015)

1. American Productivity Audit.tw.

2. "angina-related limitations at work question?aire".tw.

3. endicott work productivity scale.tw.

4. "health and labo?r question?aire".tw.

5. "health and performance question?aire".tw.

6. "health and productivity question?aire".tw.

7. "health and work question?aire".tw.

8. health-related productivity question?aire*.tw.

9. "lam employment absence and productivity scale".tw.

10. (migraine disability assessment adj2 (question?aire or survey or scale or score*)).tw.

11. MIDAS.tw. and migraine*.mp.

12. 10 or 11

13. (productiv* or presenteeism or absenteeism or work* or employ*).mp.

14. 12 and 13

15. "migraine work and productivity loss question?aire".tw.

16. (osterhaus and (work* or productivity or presenteeism)).tw.

17. (osterhaus adj3 technique).tw.

18. "productivity and disease question?aire".tw.

19. PRODISQ.tw.

20. (quantity adj2 quality adj (method or instrument)).tw.

21. (Stanford* adj5 Presenteeism Scale).tw.

22. "work and health interview".tw.

23. work performance scale.tw.

24. "work productivity and activity impairment*".tw.

25. WPAI*.tw.

26. (US National Health and Wellness Survey).tw. and (productiv* or presenteeism or absenteeism or work*).mp.

27. "health and work performance question?aire".tw.

28. work productivity short inventory.tw.

29. wellness inventory.tw.

30. work role functioning question?aire.tw.

31. (or/1-9) or (or/14-30)

32. limit 31 to english language

33. (work productivity survey or WPS-RA).tw.

34. valuation of lost productivity.tw.

35. work limitations question?aire.tw.

36. (33 or 34 ) not 32

37. limit 36 to english language 
38. 35 not 32

39. limit 38 to english language

40. 32 or 37

41. 32 or 37 or 39

ISI platform databases:

Web of Science (1900-November 6, 2015)

\# 1 TS="angina-related limitations at work questionnaire"

\# 2 ((TS="endicott work productivity scale")) AND Language $=($ English $)$

\# 3 (TS=("health and labor questionnaire" OR "health and labour questionnaire")) AND Language $=($ English $)$

\# 4 ((TS="health and productivity questionnaire")) AND Language $=($ English $)$

\# 5. ((TS="health and work questionnaire")) AND Language $=($ English $)$

\# 6. ((TS="health-related productivity questionnaire")) AND Language $=($ English $)$

\# 7. ((TS="lam employment absence and productivity scale")) AND Language $=($ English $)$

\# 8. 8 ((TS="migraine work and productivity loss questionnaire")) AND Language $=($ English $)$

\# 9. ((TS="Stanford Presenteeism Scale")) AND Language=(English)

\# 10. ((TS="health and work performance questionnaire")) AND Language $=($ English $)$

\# 11. ((TS="work and health interview")) AND Language $=($ English $)$

\# 12. ((TS="work performance scale")) AND Language=(English)

\# 13. ((TS="work productivity short inventory")) AND Language $=($ English $)$

\# 14. ((TS="American Productivity Audit")) AND Language $=($ English $)$

\# 15. $((\mathrm{TS}=($ osterhaus and (work or productivity $))))$ AND Language $=($ English $)$

\# 16. TS=("work productivity and activity impairment*")

\# 17. TS=WPAI*

\# 18. TS="wellness inventory"

\# 19. TS=("work productivity survey")

\# 20. TS=("Work role functioning*" SAME limitations)

\# 21. TS=(osterhaus SAME technique)

\# 22. TS=("productivity and disease questionnaire")

\# 23. (TS=(migraine disability assessment SAME (score* OR scale OR questionnaire OR survey) $)$ ) AND Language $=($ English $)$

\# 24. (TS=(MIDAS AND migraine $)$ ) AND Language $=($ English $)$

\# 25. (TS=Osterhaus) AND Language $=($ English $)$

\# 26. (\#23 OR \#24 OR \#25) AND Language=(English)

\# 27. (TS $=$ (work* or productivity or performance or presenteeism or absenteeism or employ*)) AND Language $=($ English $)$

\# 28. (\#26 AND \#27) AND Language=(English)

\# 29. (TS=("work role functioning questionnaire")) AND Language $=($ English $)$

\# 30. (TS="health and performance questionnaire") AND Language $=($ English $)$

\# 31. TS=("valuation of lost productivity")

\# 32. TS=("work limitations questionnaire")
\#33. (\#1 OR \#2 OR \#3 OR \#4 OR \#5 OR \#6 OR \#7 OR \#8 OR \#9 OR \#10 OR \#11 OR \#12 OR \#13 OR \#14 OR \#15 OR \#16 OR \#17 OR \#18 OR \#19 OR \#20 OR \#21 OR \#22 OR \#28 OR \#29 OR \#30 OR \#31 OR \#32) AND Language $=($ English $)$

EBSCO databases:

CINAHL (1937-November 6, 2015)

Business Source Complete (1886-November 6, 2015)

\begin{tabular}{|c|c|}
\hline $\begin{array}{r}\text { Search } \\
\text { ID\# }\end{array}$ & Search terms \\
\hline S28 & $\begin{array}{l}\mathrm{S} 1 \text { or } \mathrm{S} 2 \text { or } \mathrm{S} 3 \text { or } \mathrm{S} 4 \text { or } \mathrm{S} 5 \text { or } \mathrm{S} 6 \text { or } \mathrm{S} 7 \text { or } \mathrm{S} 8 \text { or } \mathrm{S} 9 \text { or } \mathrm{S} 10 \text { or } \\
\mathrm{S} 11 \text { or } \mathrm{S} 12 \text { or } \mathrm{S} 13 \text { or } \mathrm{S} 14 \text { or } \mathrm{S} 15 \text { or } \mathrm{S} 16 \text { or } \mathrm{S} 17 \text { or } \mathrm{S} 18 \text { or } \\
\mathrm{S} 19 \text { or } \mathrm{S} 20 \text { or } \mathrm{S} 21 \text { or } \mathrm{S} 22 \text { or } \mathrm{S} 23 \text { or } \mathrm{S} 24 \text { or } \mathrm{S} 25\end{array}$ \\
\hline S25 & "work limitations questionnaire" \\
\hline S24 & "valuation of lost productivity" \\
\hline S23 & "work productivity survey" \\
\hline S22 & "health and performance questionnaire" \\
\hline $\mathrm{S} 21$ & "productivity and disease questionnaire" \\
\hline $\mathrm{S} 20$ & $\begin{array}{l}\text { osterhaus AND (technique or presenteeism or absenteeism or } \\
\text { productivity or work* or employ*) }\end{array}$ \\
\hline S19 & "Work role functioning questionnaire" \\
\hline S18 & "wellness inventory" \\
\hline S17 & WPAI* \\
\hline S16 & "work productivity and activity impairment*" \\
\hline S15 & "American Productivity Audit" \\
\hline S14 & "work productivity short inventory" \\
\hline $\mathrm{S} 13$ & "work performance scale" \\
\hline $\mathrm{S} 12$ & "work and health interview" \\
\hline S11 & "health and work performance questionnaire" \\
\hline $\mathrm{S} 10$ & "Stanford Presenteeism Scale" \\
\hline S9 & "migraine work and productivity loss questionnaire" \\
\hline S8 & "lam employment absence and productivity scale" \\
\hline S7 & $\begin{array}{l}\text { ((“migraine disability assessment” n2 (score* or scale or } \\
\text { survey or questionnaire)) OR (MIDAS AND migraine)) } \\
\text { AND (work* OR productivity OR presenteeism OR } \\
\text { absenteeism OR employ*) }\end{array}$ \\
\hline S6 & "health-related productivity questionnaire" \\
\hline S5 & "health and work questionnaire" \\
\hline S4 & "health and productivity questionnaire" \\
\hline $\mathrm{S} 3$ & $\begin{array}{l}\text { ("health and labor questionnaire") OR ("health and labour } \\
\text { questionnaire") }\end{array}$ \\
\hline $\mathrm{S} 2$ & "endicott work productivity scale" \\
\hline S1 & "angina-related limitations at work questionnaire" \\
\hline
\end{tabular}

Proquest databases:

ABI Inform (1970-November 6, 2015)

ALL ((“American Productivity Audit”) OR ("angina-related limitations at work questionnaire") OR ("endicott work productivity scale") OR ("health and labor questionnaire") OR ("health and labour questionnaire") OR ("health and productivity questionnaire") OR ("health and work questionnaire") OR ("health and performance questionnaire") OR ("health-related productivity questionnaire") OR ("lam employment absence and productivity scale") OR ("migraine work and productivity loss questionnaire") OR ("Stanford 
Presenteeism Scale") OR ("work performance scale") OR ("work and health interview") OR ("health and work performance questionnaire") OR ("productivity and disease questionnaire") OR WPAI* OR ("work productivity and activity impairment*") OR ("work productivity short inventory") OR ("wellness inventory") OR ("work role functioning questionnaire") OR ("valuation of lost productivity") OR ("work productivity survey") OR ("work limitations questionnaire") OR ((("migraine disability assessment questionnaire") OR (MIDAS AND migraine) OR Osterhaus) AND (productivity or presenteeism or work* or employ*))

Open Access This article is distributed under the terms of the Creative Commons Attribution 4.0 International License (http:// creativecommons.org/licenses/by/4.0/), which permits unrestricted use, distribution, and reproduction in any medium, provided you give appropriate credit to the original author(s) and the source, provide a link to the Creative Commons license, and indicate if changes were made.

\section{References}

Papers of particular interest, published recently, have been highlighted as:

- Of importance

1. Murray CJ, Vos T, Lozano R, Naghavi M, Flaxman AD, Michaud C, et al. Disability-adjusted life years (DALYs) for 291 diseases and injuries in 21 regions, 1990-2010: a systematic analysis for the Global Burden of Disease Study 2010. Lancet. 2012;380(9859):2197-223.

2. Gabriel SE, Michaud K. Epidemiological studies in incidence, prevalence, mortality, and comorbidity of the rheumatic diseases. Arthritis Res Ther. 2009;11(3):229.

3. Burton W, Morrison A, MacLean R, Ruderman E. Systematic review of studies of productivity loss due to rheumatoid arthritis. Occup Med (Lond). 2006;56(1):18-27.

4. Verstappen SM, Bijlsma JW, Verkleij H, Buskens E, Blaauw AA, ter Borg EJ, et al. Overview of work disability in rheumatoid arthritis patients as observed in cross-sectional and longitudinal surveys. Arthritis Rheum. 2004;51(3):488-97.

5. Boonen A, Chorus A, Miedema H, van der Heijde D, van der Tempel H, van der Linden S. Employment, work disability, and work days lost in patients with ankylosing spondylitis: a cross sectional study of Dutch patients. Ann Rheum Dis. 2001;60(4):353-8.

6. Verstappen SM. Rheumatoid arthritis and work: the impact of rheumatoid arthritis on absenteeism and presenteeism. Best Pract Res Clin Rheumatol. 2015;29(3):495-511.

7. ter Wee MM, Lems WF, Usan H, Gulpen A, Boonen A. The effect of biological agents on work participation in rheumatoid arthritis patients: a systematic review. Ann Rheum Dis. 2012;71(2):161-71.

8. Tillett $\mathrm{W}$, de-Vries C, McHugh NJ. Work disability in psoriatic arthritis: a systematic review. Rheumatology (Oxford). 2012;51(2):275-83.

9. Sloman J, Wride A, Garrat D. "Introducing Economics" in Economics. 8th ed. Harlow, New York: Pearson; 2012.

10. Prasad M, Wahlqvist P, Shikiar R, Shih YC. A review of self-report instruments measuring health-related work productivity: a patientreported outcomes perspective. Pharmacoeconomics. 2004;22(4): 225-44.

11. Mattke S, Balakrishnan A, Bergamo G, Newberry SJ. A review of methods to measure health-related productivity loss. Am J Manag Care. 2007;13(4):211-7.
12. Zhang W, Bansback N, Anis AH. Measuring and valuing productivity loss due to poor health: a critical review. Soc Sci Med. 2011;72(2):185-92.

13. Krol M, Brouwer W. How to estimate productivity costs in economic evaluations. Pharmacoeconomics. 2014;32(4):335-44.

14. Escorpizo R, Bombardier C, Boonen A, Hazes JM, Lacaille D, Strand V, et al. Worker productivity outcome measures in arthritis. J Rheumatol. 2007;34(6):1372-80.

15. Brooks A, Hagen SE, Sathyanarayanan S, Schultz AB, Edington DW. Presenteeism: critical issues. J Occup Environ Med. 2010;52(11):1055-67.

16. Verstappen SM, Fautrel B, Dadoun S, Symmons DP, Boonen A. Methodological issues when measuring paid productivity loss in patients with arthritis using biologic therapies: an overview of the literature. Rheumatology (Oxford). 2012;51(2):216-29.

17. Koopmanschap MA, van Ineveld BM. Towards a new approach for estimating indirect costs of disease. Soc Sci Med. 1992;34(9): 1005-10.

18. Lensberg BR, Drummond MF, Danchenko N, Despiegel N, Francois C. Challenges in measuring and valuing productivity costs, and their relevance in mood disorders. Clinicoecon Outcome Res. 2013;5:565-73.

19. Pauly MV, Nicholson S, Polsky D, Berger ML, Sharda C. Valuing reductions in on-the-job illness: 'presenteeism' from managerial and economic perspectives. Health Econ. 2008;17(4):469-85.

20. CRD. Systematic Reviews: CRD's guidance for undertaking reviews in health care. Third ed. University of York; 2009.

21. Ospina MB, Dennett L, Waye A, Jacobs P, Thompson AH. A systematic review of measurement properties of instruments assessing presenteeism. Am J Manag Care. 2015;21(2):e171-85. This review focuses on identifying all measures of presenteeism, general or disease-specific, and evaluates the psychometric properties of each presenteeism instrument.

22. Osterhaus JT, Purcaru O, Richard L. Discriminant validity, responsiveness and reliability of the rheumatoid arthritis-specific Work Productivity Survey (WPS-RA). Arthritis Res Ther. 2009;11(3):R73.

23. Jette AM, Davies AR, Cleary PD, Calkins DR, Rubenstein LV, Fink A, et al. The functional status questionnaire: reliability and validity when used in primary care. J Gen Intern Med. 1986;1(3):143-9.

24. Reilly MC, Zbrozek AS, Dukes EM. The validity and reproducibility of a work productivity and activity impairment instrument. Pharmacoeconomics. 1993;4(5):353-65.

25. van Roijen L, Essink-Bot ML, Koopmanschap MA, Bonsel G, Rutten FF. Labor and health status in economic evaluation of health care. The Health and Labor Questionnaire. Int J Technol Assess Health Care. 1996;12(3):405-15.

26. Endicott J, Nee J. Endicott Work Productivity Scale (EWPS): a new measure to assess treatment effects. Psychopharmacol Bull. 1997;33(1):13-6.

27. Kopec JA, Esdaile JM. Occupational role performance in persons with back pain. Disabil Rehabil. 1998;20(10):373-9.

28. Brouwer WB, Koopmanschap MA, Rutten FF. Productivity losses without absence: measurement validation and empirical evidence. Health Policy. 1999;48(1):13-27.

29. Burton WN, Conti DJ, Chen CY, Schultz AB, Edington DW. The role of health risk factors and disease on worker productivity. $\mathrm{J}$ Occup Environ Med. 1999;41(10):863-77.

30. Amick III BC, Lerner D, Rogers WH, Rooney T, Katz JN. A review of health-related work outcome measures and their uses, and recommended measures. Spine (Phila Pa 1976). 2000;25(24):3152-60.

31. Lerner D, Amick III BC, Rogers WH, Malspeis S, Bungay K, Cynn D. The work limitations questionnaire. Med Care. 2001;39(1):72-85.

32. Pelletier KR, Koopman C. Standford/American health association presenteeism scale (SAHAPS). In: Lynch W, Riedel J, editors. Measuring employee productivity: a guide to self-assessment tools. Scottsdale, AZ: Institute for Health and Productivity Management $67 ; 2001$. 
33. Koopman C, Pelletier KR, Murray JF, Sharda CE, Berger ML, Turpin RS, et al. Stanford presenteeism scale: health status and employee productivity. J Occup Environ Med. 2002;44(1):14-20.

34. Gilworth G, Chamberlain MA, Harvey A, Woodhouse A, Smith J, Smyth MG, et al. Development of a work instability scale for rheumatoid arthritis. Arthritis Rheum. 2003;49(3):349-54.

35. Goetzel RZ, Ozminkowski RJ, Long SR. Development and reliability analysis of the Work Productivity Short Inventory (WPSI) instrument measuring employee health and productivity. J Occup Environ Med. 2003;45(7):743-62.

36. Kessler RC, Barber C, Beck A, Berglund P, Cleary PD, McKenas $\mathrm{D}$, et al. The world health organization health and work performance questionnaire (HPQ). J Occup Environ Med. 2003;45(2): 156-74.

37. Kumar RN, Hass SL, Li JZ, Nickens DJ, Daenzer CL, Wathen LK. Validation of the Health-Related Productivity Questionnaire Diary (HRPQ-D) on a sample of patients with infectious mononucleosis: results from a phase 1 multicenter clinical trial. J Occup Environ Med. 2003;45(8):899-907.

38. Shikiar R, Halpern MT, Rentz AM, Khan ZM. Development of the Health and Work Questionnaire (HWQ): an instrument for assessing workplace productivity in relation to worker health. Work. 2004;22(3):219-29.

39. Stewart WF, Ricci JA, Leotta C, Chee E. Validation of the work and health interview. Pharmacoeconomics. 2004;22(17):1127-40.

40. Turpin RS, Ozminkowski RJ, Sharda CE, Collins JJ, Berger ML, Billotti GM, et al. Reliability and validity of the Stanford Presenteeism Scale. J Occup Environ Med. 2004;46(11):1123-33.

41. Ilmarinen J. The Work Ability Index (WAI). J Occup Environ Med Am Coll Occup Environ Med. 2007;57(2):160.
42. Prochaska JO, Evers KE, Johnson JL, Castle PH, Prochaska JM, Sears LE, et al. The well-being assessment for productivity: a wellbeing approach to presenteeism. J Occup Environ Med. 2011;53(7): 735-42.

43. Zhang W, Bansback N, Boonen A, Severens JL, Anis AH. Development of a composite questionnaire, the valuation of lost productivity, to value productivity losses: application in rheumatoid arthritis. Value Health. 2012;15(1):46-54. This study describes the development of the valuation of lost productivity (VOLP) questionnaire. It is the only identified presenteeism instrument that explicitly discussed the economic theory of productivity and how it was used to inform the design of the VOLP.

44. Boezeman EJ, Sluiter JK, Nieuwenhuijsen K. Measuring work functioning: validity of a weighted composite work functioning approach. J Occup Rehabil. 2015;25(3):537-42.

45. Bouwmans C, Krol M, Severens H, Koopmanschap M, Brouwer W, Hakkaart-van RL. The iMTA productivity cost questionnaire: a standardized instrument for measuring and valuing health-related productivity losses. Value Health. 2015;18(6):753-8.

46. Koopmanschap MA. PRODISQ: a modular questionnaire on productivity and disease for economic evaluation studies. Expert Rev Pharmacoecon Outcome Res. 2005;5(1):23-8.

47. Noben CY, Evers SM, Nijhuis FJ, de Rijk AE. Quality appraisal of generic self-reported instruments measuring health-related productivity changes: a systematic review. BMC Public Health. 2014;14: 115.

48. Tang K, Boonen A, Verstappen SM, Escorpizo R, Luime JJ, Lacaille D, et al. Worker productivity outcome measures: OMERACT filter evidence and agenda for future research. J Rheumatol. 2014;41(1):165-76. 